\title{
The deployment of attention in short-term memory tasks: Trade-offs between immediate and delayed deployment
}

\author{
Michael F. Bunting and Nelson Cowan \\ University of Missouri, Columbia, Missouri \\ AND \\ Greg H. COLflesh \\ University of Illinois, Chicago, Illinois
}

\begin{abstract}
Memory at times depends on attention, as when attention is used to encode incoming, serial verbal information. When encoding and rehearsal are difficult or when attention is divided during list presentation, more attention is needed in the time following the presentation and just preceding the response. Across 12 experimental conditions observed in several experiments, we demonstrated this by introducing a nonverbal task with three levels of effort (no task, a natural nonverbal task, or an unnatural version of the task) during a brief retention interval in a short-term digit recall task. Interference from the task during the retention interval was greater when resources were drawn away from the encoding of the stimuli by other factors, including unpredictability of the end point of the list, rapid presentation, and a secondary task during list presentation. When those conditions complicate encoding of the list, we argue, attention is needed after the list so that the contents of passive memory (i.e., postcategorical phonological storage and/or precategorical sensory memory) may be retrieved and become the focus of attention for recall.
\end{abstract}

Although attention is a critical concept in cognitive psychology, it has always been a complex one, with different connotations for different researchers. We take it to mean a central, limited-capacity resource that can be voluntarily applied to both processing, or manipulation, of stored information and temporary memory storage itself (see Baddeley \& Hitch, 1974; Cowan, 2005a, 2005b; Engle, Kane, \& Tuholski, 1999; Kane et al., 2004). The central aspect indicates that the resource is shared between all modalities (vision, hearing, etc.) and types of coding (phonological, orthographic, spatial, etc.). The limited-capacity aspect indicates that one type of storage or processing can be increased only at the expense of other types. The allocation of attention can be modified voluntarily, as is indicated when participants modify their allocation according to variable instructions or payoffs. (This does not imply that attention is completely voluntary; for example, a thunderclap can recruit attention away from an assigned task momentarily.)

The most difficult aspect of attention is that not all processes fall in its domain; some types of process - notably, very well learned ones - are impervious to the allocation of attention (Shiffrin, 1988). Also, task trade-offs that are not central in nature are not considered to demonstrate attention. For instance, if performance in a listening task trades off with that in a reading task but not with that in a maze navigation task, whereas performance in a picture- matching task trades off with maze navigation but not with reading, the trade-offs are said to result from linguistic and spatial processing interference, respectively, and not from limited attention.

Our thesis is that there is a domain-general, limited attentional resource for which storage and processing compete. Perhaps to simplify the theoretical role of attention, several theorists have proposed that attention is used for processing and, perhaps, for some memory-maintenance activities, but not for memory storage itself, which is considered passive or automatic once the information has been suitably encoded (Baddeley, 1986, 2007; Baddeley \& Logie, 1999). However, this simplification makes it difficult to explain some tradeoffs, such as some of those demonstrated by Baddeley and Hitch (1974), and is in need of further study. If it can be shown that attention is needed to convert information to a form in which it can be recalled, that will be a first step in demonstrating that attention is used for storage.

At least two theoretical analyses of working memory suggest that attention should be needed for storage. First, according to suggestions of Cowan $(1988,1995,2001)$, a limited amount of information can be held in the focus of attention (on average, three to five meaningful chunks), and deliberate responses require that the information be transferred there, rather than remaining in the activated portion of long-term memory outside of attention. (For a slightly

M. F. Bunting, mbunting@casl.umd.edu 
different version of this type of view, see Oberauer, 2005.) According to this view, also, the limit in processing occurs because only a limited number of chunks of information can be held in the focus of attention and these chunks sometimes must include the task goals and instructions (especially when conflicting responses are activated, as in Kane \& Engle, 2003), which then would be expected to compete with the data being stored in the focus of attention. That expected competition between processing and storage was examined by Daneman and Carpenter (1980) and by Turner and Engle (1989), but not in a way that pits verbal storage against nonverbal processing, as in the present study. Second, according to Baddeley $(2000,2007)$, abstract information (neither purely phonological nor purely visuospatial in nature) can be held in a newly noted capacity-limited component of working memory termed the episodic buffer. Baddeley $(2000,2007)$ suggested that attention may be needed for storage in this buffer, unlike what he assumes (Baddeley, 1986) to be the case for phonological and visuospatial storage. Also, presumably, attention is needed to carry out processing in the case of stimulus-response incompatibility, so this too could suggest a trade-off between our two tasks (verbal storage and nonverbal processing).

To help evaluate these possibilities, we describe a speededtask procedure that was used to assess the role of attention during a brief retention interval in running and fixed-length short-term recall tasks. A trade-off between two tasks (on the one hand, the transfer of auditory-verbal information to a retrievable form and, on the other hand, a speeded visuospatial response task with two levels of stimulus-response compatibility) would be evidence of competition between processing and storage for a shared attentional resource.

\section{The Speeded, Intervening Task Procedure}

The speeded task interposed between memory stimuli and memory response was a manual response analogue of the prosaccade/antisaccade task (Hallett, 1978) in which an individual is to look toward a target (prosaccade condition) or, with more difficulty, away from the target (antisaccade condition). The speeded task was interpolated between the presentation and the recall phases of short-term recall. To avoid the problem of confounding effects from shared specific processes, we used two versions of the speeded task that were physically identical but differed in the demand for attention (a research strategy used previously by Watkins, Watkins, Craik, \& Mazuryk, 1973). Moreover, the speeded task and the short-term recall tasks did not seem to share modality or other specific processes.

An eyetracking instrument is typically used to measure gaze direction and duration, but some (Friedman \& Miyake, 2004b; Roberts, Hager, \& Heron, 1994) have devised manual keypress and reaction time (RT) experiments to infer when participants make a prosaccade response in an antisaccade condition. Likewise, in our speeded task, a centered fixation point and then a box appeared on either side of the display. The participants made a manual keypress response that corresponded either to the same side of the screen (less demanding) or to the opposite side (more demanding). We shall refer to these as the propress and the antipress responses, respectively. The speeded-task proce- dure used in these experiments is illustrated in Figure 1. We predicted that responding in the antipress condition in our speeded task would require more attention than would responding in the propress condition, thereby creating a conflict when attention is needed to extract information from sensory memory or for retrieval of information into the focus of attention. The propress condition is likely to demand some attention (because of the need to respond), although not as much as the antipress condition.

\section{Memory-Task-Dependent Expectations}

The principal analyses will focus on the effects of the speeded task on short-term recall tasks designed to prevent active updating and rehearsal during the presentation of the memoranda. These were the running memory span task with a rapid presentation rate (Experiment 1A) and ordinary list recall with the added requirement of articulatory suppression (Experiment 2A). Encoding during presentation of the memoranda is difficult under these task conditions for different reasons. Several methodological properties of the running span task differentiate it from typical fixed-list or simple span tasks. Running span presents an unpredictable number of items in sequence and requires recall from the end of the list (Pollack, Johnson, \& Knaff, 1959). For example, we presented 12-20 spoken digits at random, and the task was to recall the final 6 digits. A common assumption about running span procedures is that they involve an active process of continually updating a working memory register and holding just the final few items. Although this might be feasible if the items are presented slowly, the items in our version of running span are presented quickly so as to minimize the opportunity for rehearsal (see Bunting, Cowan, \& Saults, 2006; Hockey, 1973). Thus, the rapid rate of presentation, together with the unpredictable list length, makes covert rehearsal or active processing of the items extremely unlikely, or at least unhelpful.

In an ordinary span task, such as the fixed-length list task in Experiments 2A-2C, articulatory suppression, rather than unpredictability and a rapid presentation rate, prevents rehearsal (Baddeley, 1986). Articulatory suppression may not interfere with encoding but at least prevents subvocal rehearsal. Baddeley (2007) has argued that items presented auditorily, as were the items in all of our experiments, gain automatic access to the phonological loop. However, articulatory suppression prevents subvocal rehearsal, as indicated by the fact that the word length effect is not obtained under such conditions. Furthermore, Cowan, Cartwright, Winterowd, and Sherk (1987) found that even when items are acoustic, an articulatory code is not completely used automatically under articulatory suppression conditions, as evidenced by a much reduced phonological similarity effect.

We thus feel confident that what is vulnerable to distraction in running span at the rapid presentation rate or ordinary list span with articulatory suppression is, if anything, the process of extracting information from a passively held form of storage into an active, capacity-limited holding mechanism, such as the focus of attention (Cowan, 2001) or the episodic buffer (Baddeley, 2000). We remain agnostic as to how the memoranda are maintained prior to recall. Cowan $(1984,1988)$ suggested that there are two forms of 


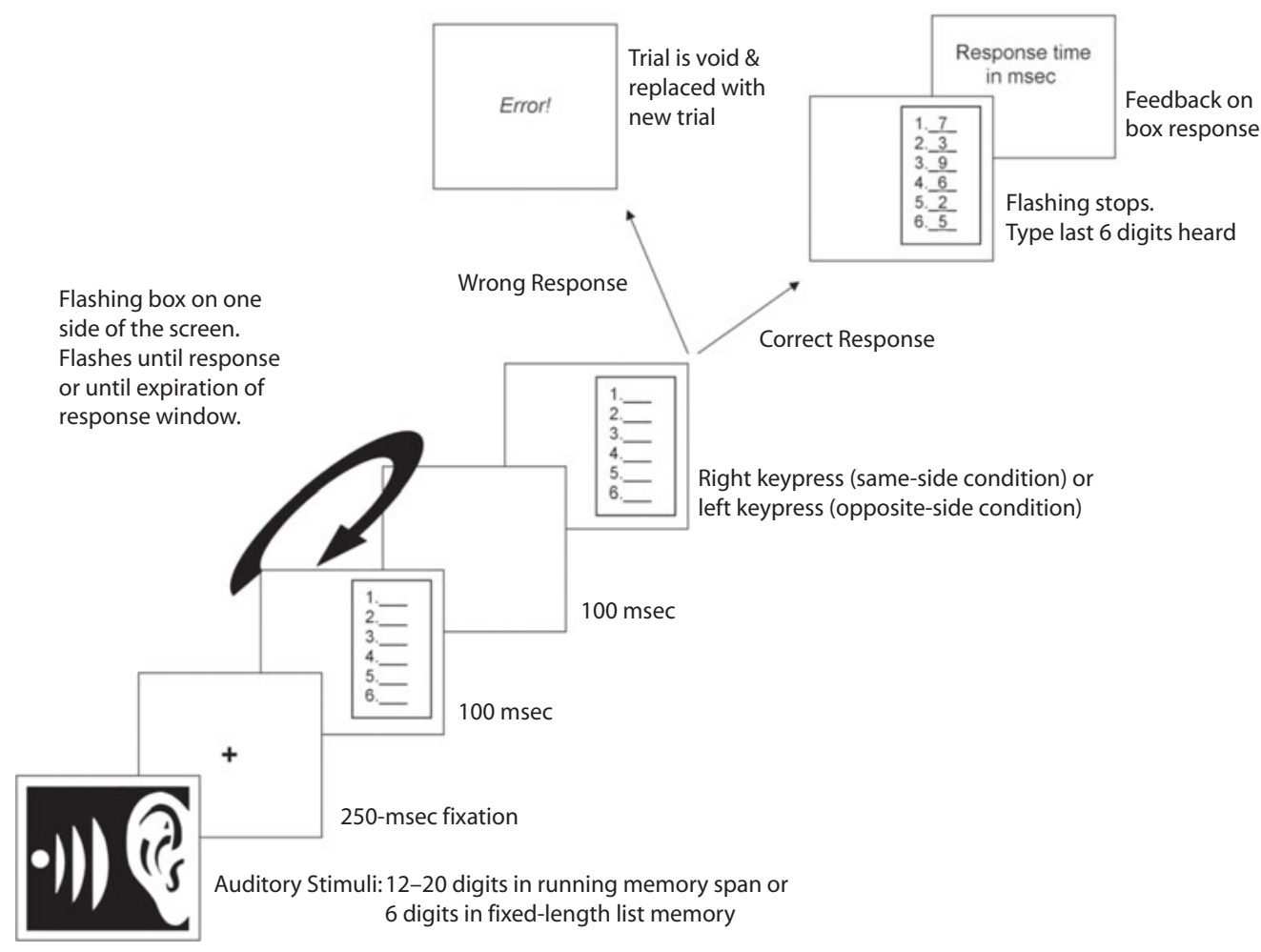

Figure 1. General experimental design. The speeded interpolated task followed presentation of an auditory running memory span trial (12-20 random digits) or an ordinary memory span trial (6 random digits). The box flashed on either the right or the left side at random. Feedback to accurate responses in the speeded task included reaction time (RT) on the current trial, mean RT for all trials so far in the block, and encouragement to beat the current RT on the next trial. Incorrect responses on the speeded task voided the trial, and a replacement trial with the same number of digit stimuli was added at random among the remaining trials.

passive storage: a brief, precategorical echoic trace and a more processed, although passively maintained, phonological store. Participants almost certainly rely on both.

We expect that attention supplements passive storage and encoding from sensory memory when active maintenance rehearsal is difficult or impossible, and we submit that this is the case in running span at a rapid presentation rate (Experiment 1A) or in ordinary list span with articulatory suppression (Experiment 2A). Encoding during item presentation is, under these circumstances, weak in semantic or lexical elements and predominantly includes passively held components such as sensory memory. Thus, we argue that if less attention is available during list presentation, more attention is needed, in the time following the presentation and just preceding the response, to extract information from passive storage to become more meaningful units that can be used in the response. Our primary analyses will focus on the effects of the speeded task during the retention interval on these span tasks.

\section{GENERAL METHOD}

\section{Participants}

All the participants spoke English as a first language, had normal or corrected-to-normal vision, and had normal use of their dominant writing hand, which was used to type responses. All of the experiments were conducted at the University of Missouri, except Experiment 1C, which was conducted at the University of Illinois at Chicago. All the participants were recruited from undergraduate psychology participant pools and participated as part of their coursework in introductory psychology. Each participant took part in just one experiment.

\section{Tasks and Materials}

Memory tasks. The participants listened to lists of digits (the numbers 1-9) and recalled the last 6 . In the running memory span task (Experiments 1A-1D), the digit lists contained 12-20 randomized digits and ended unpredictably. List length was also randomized, but each list length from 12-20 digits was sampled equally often. As a restriction on digit randomization, repetitions of the same digit were permitted only after 5 or more intervening digits. In the ordinary memory span task (Experiments $2 \mathrm{~A}-2 \mathrm{C}$ ), the length of the digit lists was predictably fixed at 6 random, nonrepeating digits per list. In both tasks, each digit was used approximately equally often.

The memoranda were always spoken digits, which were recorded in a male voice and digitally compressed to play within $250 \mathrm{msec}$ each; although speeded, they remained easily identifiable. When recall was prompted, the participants recalled the digits by typing them on a keypad. The participants pressed the Enter key to advance to the next line after typing a digit or to leave a line blank. Use of the backspace key to edit the current line was permitted, but editing prior entries was not. The digit presentation rate, which was always constant within an experiment, was either fast (4 digits/sec) or slow ( $1 \mathrm{digit} / \mathrm{sec})$. The same compressed digits were used in every experi- 
ment, but silent periods were introduced between digits to make the presentation rate 1 digit/sec.

Dual tasks. The participants listened to the digits while performing articulatory suppression (saying "the"), while knee tapping with their nondominant hand, or while doing nothing (the dual-task control condition). The articulation/tapping rate was approximately 2 responses/sec and was practiced before being used in the list memory task. The participants discontinued articulatory suppression or knee tapping during digit recall.

Speeded interpolated task. ${ }^{1}$ The speeded interpolated task was a visual computerized task requiring a keypress response. The visual stimulus was a $3 \times 6$ in. vertically oriented rectangle that contained six horizontal lines numbered 1-6. The box and lines were black on a white background. The box randomly appeared vertically centered and horizontally justified on the left or right side of the screen and flashed on and off at 100-msec intervals until a response or the end of the response interval. The participants pressed a key corresponding to the same or the opposite side of the screen as the flashing box, depending on the experimental condition. The "1" and " 3 " keys were additionally labeled " $\mathrm{L}$ " and " $\mathrm{R}$ " and represented the left and right sides of the screen, respectively. Right-handed participants responded with the " 1 " and " 3 " keys on the numerical keypad, and left-handed participants used the "1" and " 3 " keys from the number row in the alphanumeric keypad. The participants were instructed to make this decision rapidly, and feedback on valid trials consisted of the RT, a running tabulation of the mean RT per trial block, and encouragement to beat that mean RT on subsequent trials. Trials on which the wrong response was made were immediately void and, when the speeded task was used with running span, the memoranda were not collected, and a new trial of the same length was added at random among the remaining trials.

\section{Procedure}

The participants were tested individually in a single session lasting 55 min or less. The participants completed three task segments: (1) the speeded-task practice, which was always first, comprising pro- and antipress task trial blocks counterbalanced for order; (2) a memory span task alone; and (3) memory span combined with the speeded task. The order of Task Segments 2 and 3 was counterbalanced across participants, and the order of pro- and antipress trial blocks within each of these was counterbalanced across participants but was the same as that in Task Segment 1 .

The participants in a dual-task condition completed Task Segments 1-3 twice, once with concurrent articulatory suppression and once with concurrent knee tapping. These participants were counterbalanced for whether they first received trial blocks with concurrent articulatory suppression or tapping tasks. Within those trial blocks, though, the task order for Task Segments 1-3 was unchanged.

The speeded-task practice (Task Segment 1) consisted of 2 practice and 18 test trials each for the anti- and propress procedures.
The memory-span-only task (Task Segment 2) consisted of 2 practice and 18 test trials. The procedure for memory span combined with the speeded task is illustrated in Figure 1. This task included 2 practice and 18 test trials in each trial block, with anti- and propress speeded-task conditions performed in two separate blocks counterbalanced for order.

In the memory-span-only task, the participants were permitted unlimited RT for the memory response but were encouraged to perform it accurately and quickly. The participants initiated each trial by keypress, after which a 250 -msec visual fixation cross appeared, followed by the flashing box. Recall was permitted immediately after the offset of the digits, and the response box was vertically and horizontally centered. In the memory span task plus speeded-task condition, the participants had to make the speeded-task response under time pressure; they were permitted a period of time equivalent to their mean RT in the speeded-task practice plus one standard deviation, and longer RTs invalidated the trial. Following the speeded-task response, the participants typed the memory span digits in serial order. Responses were shown on the screen in the box that had appeared for the speeded task, a $3 \times 6$ in. rectangular response box containing six numbered lines, one for each digit from the end of the list.

\section{Design}

The design of the seven experiments and the number of participants per experiment are summarized in Table 1. The experiments have the same basic procedure, differing only with respect to the type of memory task (running or fixed), the presentation rate of the memoranda (fast or slow), and the absence or presence (and kind) of dual task (coarticulation, tapping, or none). Each memory task was followed by the speeded interpolated task with antipress, propress, and control conditions.

\section{EXPERIMENT 1A Fast Running Span (No Dual Task) \\ Results}

We first will describe the primary Experiment 1A datanamely, the effects of the speeded task on running memory span. Next, we will describe the details of the speeded task itself.

\section{Running Span}

Running span was defined simply as the mean number of digits recalled in the correct serial position. Figure 2 (E1A) depicts a main effect of running span and shows that mean running span scores were lower in the antipress condition than in the propress or the control condition, which did not differ. Statistical analyses supporting this conclusion were

Table 1

Experimental Design

\begin{tabular}{ccclc}
\hline $\begin{array}{c}\text { Experiment and } \\
\text { Condition No. }\end{array}$ & $\begin{array}{c}\text { Memory } \\
\text { Span Task(s) }\end{array}$ & $\begin{array}{c}\text { Digit } \\
\text { Presentation Rate }\end{array}$ & \multicolumn{1}{c}{ Dual Task } & $N$ (No. of Females) \\
\hline 1A & Running & fast & none & $24(10)$ \\
1B & Running & slow & none & $21(16)$ \\
1C-1 & Running & slow & coarticulation & $21(11)$ \\
1C-2 & Running & slow & tapping & $21(11)$ \\
1D-1 & Running & fast & coarticulation & $18(16)$ \\
1D-2 & Running & fast & tapping & $18(16)$ \\
2A-1 & Fixed & slow & coarticulation & $18(6)$ \\
2A-2 & Fixed & slow & tapping & $18(6)$ \\
2B-1 & Fixed & fast & coarticulation & $18(6)$ \\
2B-2 & Fixed & fast & tapping & $18(6)$ \\
2C-1 & Fixed & fast & none & $20(13)$ \\
2C-2 & Fixed & slow & none & $20(13)$ \\
\hline
\end{tabular}

Note-For experiments with multiple conditions, the same participants completed all of the tasks. 




Figure 2. The effect of the speeded interpolated task on memory for digits in all 12 task conditions across the seven experiments. The digit lists were either fixed or unpredictable, the digit presentation rate was fast (4/sec) or slow (1/sec), and the secondary task, when present, was easy (hand tapping on knee) or difficult (articulatory suppression). E1A-E2C indicate the numbered experiment that was the source of the data (e.g., E1A = Experiment $1 \mathrm{~A})$. Experimental conditions in Cluster A did not show a pro- or antipress task effect, whereas experiments in Cluster B showed both of these effects. Conditions outside of these clusters showed an antipress task effect only. Error bars are $95 \%$ within-subjects confidence intervals (Loftus \& Masson, 1994). " "Significant difference from the interpolated task control for that task. NS, effect was not significant. 
based on the proportion correct across serial positions. Specifically, an ANOVA for repeated measures tested whether running span scores, for trials with a correct speeded-task response only, varied as a function of the speeded-task conditions (antipress, propress, and control), the serial positions to be recalled (the last six positions, which we label 1-6 for convenience), or the interaction of these variables. The critical effect for our hypotheses, a main effect for the speeded task, was significant. The ANOVA and pairwise comparisons are reported in Table 4.

A significant main effect of serial position $[F(5,115)=$ $\left.101, M S_{\mathrm{e}}=.03, p<.01\right]$ indicated a strong recency advantage, as one can see in Figure 3. The interaction of speeded task and serial position was not significant $[F(10,230)=$ $1.17, M S_{\mathrm{e}}=.01, \mathrm{n} . \mathrm{s}$.]. We entertained the hypothesis that the differences between conditions in running span scores could be attributed to a small, although significant, difference in RTs to the anti- and propress decisions (described below). Lower scores for the antipress condition hypothetically could result from a slightly longer period for decay of the passive buffer information in that condition. To equate RTs for these speeded-task conditions, the 42 trials with the longest RTs among all the trials for all the participants in the antipress condition were dropped. Even with the mean RTs for the anti- and propress conditions equated (at $364 \mathrm{msec}$ ), the pattern of results for running span remained unchanged. The ANOVA main effect for the speeded task was still significant $\left[F(2,46)=7.95, M S_{\mathrm{e}}=.196, p<.01\right]$, and subsequent orthogonal pairwise comparisons still showed that the antipress condition $(M=2.07, S D=0.70)$, but not the propress condition $(M=2.45, S D=0.68)$, differed significantly from the control $(M=2.56, S D=0.75)$.

\section{Speeded Task}

Practice phase. It was predetermined that, in the speededtask practice phase, trials with RTs less than $200 \mathrm{msec}$ (none actually occurred) or greater than $1,000 \mathrm{msec}$ (reported in Table 2) would be deemed spurious and dropped from the analysis, and the computer reran those trials. Performance on the speeded-task practice was used to establish each participant's baseline performance. Means with standard deviations for errors and RTs to the anti- and propress decisions are reported in Table 2. Significant differences, as determined by paired-samples $t$ tests, are also indicated in Table 2. Statistical analyses of these data were unremarkable here and in the remaining experiments, so further discussion will be omitted to conserve space.

Speeded task combined with running span. Table 3 shows means with standard deviations for errors and RTs to the anti- and propress decisions of the speeded task when carried out along with running span. Trials with RTs under $200 \mathrm{msec}$ (one in the antipress and six in the propress condition) were excluded from the analysis, as were trials with RTs above the speeded-task practice mean plus $1 S D$ (time-out trials shown in Table 3 ).

In 10 of the 12 experimental conditions reported in Table 3, many more time-out trials occurred in the propress condition than in the antipress condition, despite the fact that the mean RTs in the practice trials were similar. This could have been due to the increase in $S D$ from single- to dual-task conditions (i.e., combining the speeded task with running span) that occurred in the propress task, but not in the antipress task. There was also a second critical factor. Specifically, comparing Tables 2 and 3 , one can see that, by the end of practice, performance appears to have reached

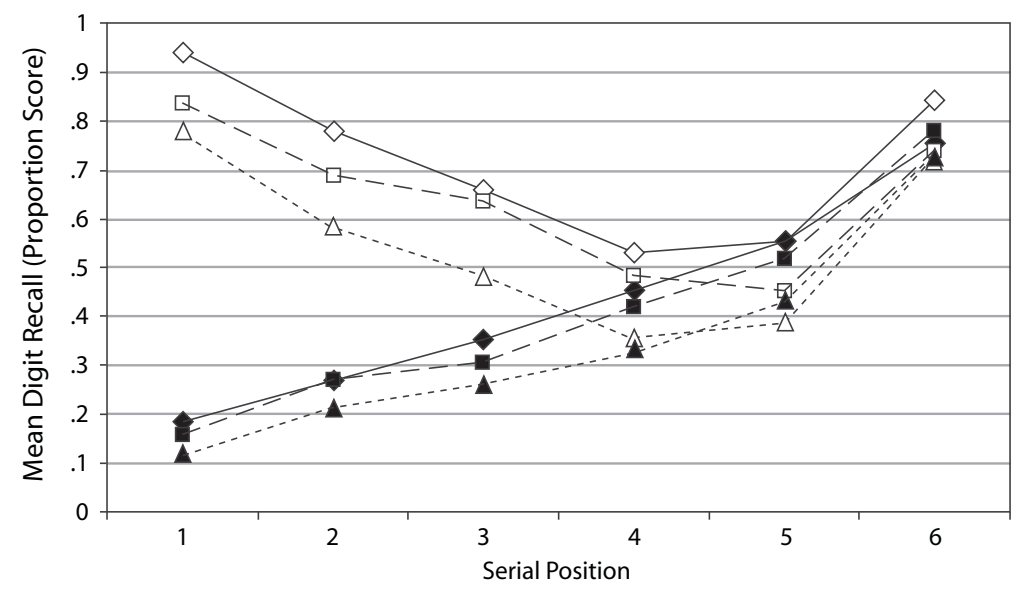

\begin{tabular}{|c|c|}
\hline $\begin{array}{c}\text { Experiment } 1 \\
- \text { Running span control (no speeded task) } \\
- \text { - Running span + Propress }\end{array}$ & $\begin{array}{c}\text { Experiment } 2 \\
-\checkmark \text { 6-item lists control (no speeded task) } \\
-\square--6 \text {-item lists + Propress } \\
-\Delta-- \text { 6-item lists + Antipress }\end{array}$ \\
\hline
\end{tabular}

Figure 3. Proportions correct for running span (Experiment 1A) and fixed-length lists with articulatory suppression (Experiment $2 \mathrm{~A}$ ) at each of six serial positions as a function of the antipress, propress, or no-press (control) speeded-decision task interpolated between the span stimuli and the responses. Data are for trials with correct speeded-task responses only. 
Table 2

Means (With Standard Deviations) for Reaction Times, Errors, and Time-Out Trials on Anti- and Propress Responses in the Speeded-Task Practice

\begin{tabular}{|c|c|c|c|c|c|c|c|c|c|c|c|c|c|c|c|c|c|}
\hline \multirow[b]{3}{*}{ Experiment } & \multirow[b]{3}{*}{ Rate } & \multirow{3}{*}{$\begin{array}{l}\text { Dual } \\
\text { Task }\end{array}$} & \multicolumn{5}{|c|}{ Reaction Time (msec) } & \multicolumn{5}{|c|}{ Errors } & \multicolumn{5}{|c|}{ Time-Out } \\
\hline & & & \multicolumn{2}{|c|}{ Anti } & \multicolumn{2}{|c|}{ Pro } & \multirow[b]{2}{*}{$t$} & \multicolumn{2}{|c|}{ Anti } & \multicolumn{2}{|c|}{ Pro } & \multirow[b]{2}{*}{$t$} & \multicolumn{2}{|c|}{ Anti } & \multicolumn{2}{|c|}{ Pro } & \multirow[b]{2}{*}{$t$} \\
\hline & & & $M$ & $S D$ & $M$ & $S D$ & & $M$ & $\overline{S D}$ & $M$ & $S D$ & & $M$ & $S D$ & $M$ & $S D$ & \\
\hline \multicolumn{18}{|c|}{ Running Memory Span } \\
\hline $1 \mathrm{~A}$ & fast & none & 397 & 53 & 363 & 19 & $3.86^{*}$ & 0.83 & 1.1 & 0.79 & 0.9 & $<1.00$ & 0.25 & 0.5 & 0.17 & 0.4 & 1.16 \\
\hline $1 \mathrm{~B}$ & slow & none & 445 & 69 & 403 & 72 & $3.63^{*}$ & 0.50 & 0.8 & 0.44 & 0.6 & $<1.00$ & 0.44 & 0.7 & 0.17 & 0.4 & 1.54 \\
\hline \multirow[t]{2}{*}{$1 \mathrm{C}$} & slow & coart & 451 & 102 & 404 & 102 & $3.62^{*}$ & 1.29 & 0.9 & 1.33 & 1.3 & $<1.00$ & 0.99 & 1.0 & 1.01 & 0.8 & $<1.00$ \\
\hline & slow & tap & 499 & 128 & 471 & 111 & 1.49 & 0.78 & 1.0 & 0.65 & 0.9 & $<1.00$ & 0.92 & 0.8 & 0.83 & 0.6 & $<1.00$ \\
\hline \multirow[t]{2}{*}{ 1D } & fast & coart & 433 & 98 & 400 & 58 & 1.71 & 1.40 & 1.2 & 1.06 & 1.0 & 1.37 & 0.94 & 0.2 & 0.90 & 0.2 & $<1.00$ \\
\hline & fast & tap & 479 & 136 & 449 & 120 & 1.68 & 1.00 & 1.1 & 0.89 & 0.5 & $<1.00$ & 1.40 & 1.6 & 1.11 & 1.1 & $<1.00$ \\
\hline \multicolumn{18}{|c|}{ Fixed-Length List Memory Span } \\
\hline \multirow[t]{2}{*}{$2 \mathrm{~A}$} & slow & coart & 411 & 62 & 370 & 41 & 1.90 & 0.44 & 0.6 & 0.39 & 0.9 & $<1.00$ & 0.91 & 1.1 & 0.32 & 0.7 & $2.37^{*}$ \\
\hline & slow & tap & 431 & 68 & 408 & 39 & 1.49 & 1.06 & 1.4 & 0.50 & 0.8 & 1.46 & 0.56 & 0.6 & 0.56 & 0.8 & $<1.00$ \\
\hline \multirow[t]{2}{*}{ 2B } & fast & coart & 419 & 72 & 388 & 54 & $2.44^{*}$ & 1.28 & 1.5 & 0.72 & 1.0 & $2.09^{*}$ & 0.59 & 0.7 & 0.72 & 1.0 & $<1.00$ \\
\hline & fast & tap & 441 & 96 & 397 & 76 & $2.75^{*}$ & 0.89 & 1.0 & 1.11 & 1.1 & $<1.00$ & 0.56 & 0.9 & 0.44 & 0.5 & $<1.00$ \\
\hline $2 \mathrm{C}$ & both & none & 381 & 49 & 351 & 36 & $2.31^{*}$ & 0.95 & 1.0 & 0.65 & 1.0 & 1.06 & 0.70 & 0.7 & 0.40 & 0.6 & 1.67 \\
\hline
\end{tabular}

Note-The speeded-task practice was not paired with a memory task, so the practice was the same across the experiments, except for the kind of dual task. "Anti" and "Pro" = the anti- and propress speeded-task conditions, respectively. "Coart" and "tap" = the coarticulation and knee-tapping dual-task conditions, respectively. Reaction times are for correct responses only. Errors (same-side keypresses on antipress trials and opposite-side keypresses on propress trials) refer to the mean number of errors out of 18 trials. "Time-Out" here refers to reaction times exceeding 1,000 msec; the mean number of these trials is shown. They were dropped from the analysis, and the computer program reran these trials. ${ }^{*} p<.05$, as determined by paired-subjects $t$ tests for the comparison of reaction times, errors, and time-outs on the anti- and propress speeded tasks.

an asymptotic speed for propress trials (which were $1 \mathrm{msec}$ longer when combined with a memory test than they were in the practice phase), whereas more improvement occurred during the memory test phase for the antipress trials (which were $15 \mathrm{msec}$ shorter when combined with a memory test than they were in the practice phase).

More errors were made in the antipress than in the propress speeded-task condition. Trials on which there was an error in the decision were dropped and did not influence the computation of mean RTs or running span scores. Accurate propress decisions were also made in significantly less time than antipress decisions. Paired-subjects $t$ tests supporting these conclusions are reported in Table 3, along with accuracy and RT data for the speeded-task responses in the remaining experiments. Subsequent discussion of these data would be redundant, so further discussion will be omitted to conserve space.

\section{Replication Experiment}

We replicated the antipress disadvantage in another experiment $(N=23)$, in which the running span task as described above served as the control condition. The manipulation new

Table 3

Means (With Standard Deviations) for Reaction Times, Errors, and Time-Out Trials on Anti- and Propress Responses in the Speeded Task, When Performed With a Memory Task

\begin{tabular}{|c|c|c|c|c|c|c|c|c|c|c|c|c|c|c|c|c|c|}
\hline \multirow[b]{3}{*}{ Experiment } & \multirow[b]{3}{*}{ Rate } & \multirow{3}{*}{$\begin{array}{l}\text { Dual } \\
\text { Task }\end{array}$} & \multicolumn{5}{|c|}{ Reaction Time (msec) } & \multicolumn{5}{|c|}{ Errors } & \multicolumn{5}{|c|}{ Time-Out } \\
\hline & & & \multicolumn{2}{|c|}{ Anti } & \multicolumn{2}{|c|}{ Pro } & \multirow[b]{2}{*}{$t$} & \multicolumn{2}{|c|}{ Anti } & \multicolumn{2}{|c|}{ Pro } & \multirow[b]{2}{*}{$t$} & \multicolumn{2}{|c|}{ Anti } & \multicolumn{2}{|c|}{ Pro } & \multirow[b]{2}{*}{$t$} \\
\hline & & & $M$ & $S D$ & $M$ & $S D$ & & $M$ & $S D$ & $M$ & $S D$ & & $M$ & $S D$ & $M$ & $S D$ & \\
\hline \multicolumn{18}{|c|}{ Running Memory Span } \\
\hline $1 \mathrm{~A}$ & fast & none & 382 & 45 & 364 & 30 & $2.10^{*}$ & 4.33 & 3.0 & 1.83 & 2.3 & $4.40^{*}$ & 2.83 & 0.5 & 2.17 & 1.8 & $<1.00$ \\
\hline $1 \mathrm{~B}$ & slow & none & 384 & 61 & 377 & 51 & $<1.00$ & 1.67 & 1.6 & 1.14 & 1.3 & 1.47 & 3.05 & 2.2 & 3.48 & 1.7 & $<1.00$ \\
\hline $1 \mathrm{C}$ & slow & coart & 393 & 68 & 372 & 50 & $2.39^{*}$ & 5.24 & 3.5 & 4.86 & 3.1 & $<1.00$ & 2.52 & 1.7 & 2.57 & 2.0 & $<1.00$ \\
\hline & slow & tap & 438 & 87 & 418 & 90 & 1.16 & 4.19 & 2.8 & 4.24 & 2.3 & $<1.00$ & 3.05 & 1.7 & 3.43 & 1.9 & $<1.00$ \\
\hline $1 \mathrm{D}$ & fast & coart & 427 & 73 & 400 & 47 & $2.15^{*}$ & 6.78 & 5.5 & 5.72 & 4.2 & 1.01 & 4.00 & 4.4 & 4.00 & 3.3 & $<1.00$ \\
\hline & fast & tap & 449 & 108 & 421 & 102 & $2.26^{*}$ & 5.94 & 4.8 & 4.00 & 2.6 & 1.49 & 3.44 & 0.5 & 3.17 & 1.2 & $<1.00$ \\
\hline \multicolumn{18}{|c|}{ Fixed-Length List Memory Span } \\
\hline \multirow[t]{2}{*}{$2 \mathrm{~A}$} & slow & coart & 406 & 59 & 389 & 66 & $<1.00$ & 5.00 & 3.0 & 3.44 & 2.0 & $2.12^{*}$ & 3.44 & 2.2 & 2.83 & 1.7 & $<1.00$ \\
\hline & slow & tap & 399 & 54 & 389 & 51 & $<1.00$ & 3.33 & 2.6 & 1.96 & 1.4 & $<1.00$ & 3.06 & 2.5 & 2.33 & 1.6 & $<1.00$ \\
\hline \multirow[t]{2}{*}{$2 \mathrm{~B}$} & fast & coart & 383 & 63 & 362 & 43 & 1.69 & 4.72 & 3.7 & 3.83 & 3.9 & $<1.00$ & 3.39 & 1.8 & 3.11 & 2.6 & $<1.00$ \\
\hline & fast & tap & 390 & 64 & 364 & 55 & $3.12^{*}$ & 4.39 & 2.7 & 4.11 & 2.6 & $<1.00$ & 3.17 & 2.0 & 3.28 & 1.7 & $<1.00$ \\
\hline \multirow[t]{2}{*}{$2 \mathrm{C}$} & fast & none & 351 & 25 & 341 & 34 & 1.44 & 3.10 & 3.5 & 1.20 & 1.7 & $2.60^{*}$ & 4.05 & 2.8 & 1.75 & 2.0 & $3.81^{*}$ \\
\hline & slow & none & 366 & 24 & 345 & 26 & $6.29^{*}$ & 4.75 & 3.7 & 3.80 & 3.9 & 1.25 & 3.35 & 2.5 & 2.20 & 2.0 & $2.60^{*}$ \\
\hline
\end{tabular}

Note- "Anti" and "Pro" = the anti- and propress speeded-task conditions, respectively. "Coart" and "tap" = the coarticulation and knee-tapping dual-task conditions, respectively. Reaction times are for correct responses only. Errors (same-side keypresses on antipress trials and opposite-side keypresses on propress trials) refer to the mean number of errors out of 18 trials. "Time-Out" here refers to reaction times exceeding the participant's speeded-task practice mean plus $1 S D$. They were dropped from the analysis, and the computer program reran those trials. ${ }^{*} p<.05$, as determined by paired-subjects $t$ tests for the comparison of reaction times, errors, and time-outs on the anti- and propress speeded tasks. 
to that experiment (proactive interference from previous items; for details, see the Appendix) did not prove effective, but the control condition was nonetheless important, since it replicated the antipress disadvantage with new participants in a different experimental context. A repeated measures ANOVA identified a speeded-task effect in an analysis of the antipress, propress, and control conditions $[F(2,44)=$ $\left.4.18, M S_{\mathrm{e}}=.26, p<.02\right]$. Orthogonal pairwise comparisons confirmed that span scores were significantly lower in the antipress condition $(M=2.12, S D=0.71)$ than in either the propress $(M=2.48, S D=0.83)$ or the control $(M=2.50$, $S D=0.75$ ) condition, which themselves did not differ.

\section{Discussion}

We favor the view that attention is used in a running span task with a fast presentation in a way in which it is not used in many other forms of recall. Specifically, given that it is impossible to update a capacity-limited, attention-demanding store as the list presentation proceeds, after the list ends it is necessary for attention to be focused on an unanalyzed sensory and/or phonological record to allow the extraction of items into the limited store at that time. The results of Experiment 1A are consistent with that hypothesis, along with the corollary that a speeded, interpolated task can compromise working memory when it, too, depends on the same attentional resource (Cowan, 2001; Cowan et al., 2005). Specifically, the fact that the antipress condition interfered with running span suggests that there is a shared attentional resource.

The fact that the effect of the nature of the speeded task was relatively small ( $0.4-0.5$ item) suggests that storage may rely only partly on the shared resource. Cowan $(1988,1995$, 2001) allowed for activated memory outside of the focus of attention, serving a function comparable to passive memory buffers. In the present experiment, it could take the form of both auditory sensory and phonological memory representations of the spoken digits. The reason that the effect of distraction was not even larger than it was could be that the memory retrieval process could return to a passive store after the completion of the interpolated, speeded-decision task, albeit to a store that, by then, was somewhat degraded. We would thus anticipate more forgetting were the retention interval longer, although we did not test this prediction.

However, we did test several other hypotheses regarding the effect of the conditions during encoding on final recall. To anticipate the outcome, these factors-speed of the digit presentation, and the presence or absence (and difficulty when present) of distraction during encoding had systematic effects when acting in unison.

\section{EXPERIMENT 1B}

\section{Slow Running Span (No Dual Task)}

We provided time for rehearsal during the running span task, thereby reducing the need to use attention in the apperception of the running span items (Hockey, 1973). As is indicated in Table 1, the task requirements remained unchanged from Experiment 1A, but for the decrease in the presentation rate. (Experiment $1 \mathrm{~B}$ was the control condition in a larger experiment, the details of which will be described in the Appendix.) Mean running span scores are depicted in Figure 2 (E1B). A repeated measures ANOVA failed to detect a difference among the antipress, propress, and control (no speeded task) conditions $[F(2,40)=1.41$, $M S_{\mathrm{e}}=.83$, n.s.]. Thus, the speeded task failed to have a statistically significant effect on memory for the running span digits when we slowed the presentation rate to permit active updating and rehearsal during encoding.

\section{EXPERIMENT 1C Slow Running Span With Concurrent Tasks}

A tacit assumption of the experiments thus far has been that a rapid presentation rate has much the same effect as articulatory suppression on encoding. In this experiment, articulatory suppression was added during encoding on the slow-paced running span task to prevent rehearsal. A nonverbal dual task, knee tapping with the nondominant hand during presentation of the memoranda, was implemented separately and served as a comparison.

Mean running span scores for the tasks with coarticulation and tapping are depicted in Figure 2 (E1C). The interpolated speeded task significantly affected memory for the running span digits in both the task with articulatory suppression and the task with tapping. ANOVAs and pairwise comparisons for these simple effects are given in Table 4. [The experiment-specific interaction between speeded-task condition (antipress, propress, and control) and dual-task distraction during encoding (articulatory suppression and tapping) was evaluated by means of a repeated measures ANOVA but was not significant; $F(2,40)=1.40, M S_{\mathrm{e}}=.21$, n.s.]

Articulatory suppression made encoding the running span digits difficult, in spite of the fact that the presentation rate was slowed to permit rehearsal. This is evidenced in the negative effect of the speeded task (anti and pro) on running memory span. Tapping had less impact on encoding, as indicated by the significant difference between scores in the pro- and antipress conditions of the task with tapping.

\section{EXPERIMENT 1D \\ Fast Running Span With Concurrent Tasks}

This final running span experiment demonstrates the combined effects of unpredictability, speeded presentation rate, and dual-task distraction during encoding on final recall. The prediction was that any distraction, even the propress speeded task, during the retention interval would hurt performance, relative to the no-press control. At the rapid rate of presentation, articulatory suppression not only would make rehearsal all the more impossible, but also would make scheduling the speeded-task responses difficult as well. We speculated that tapping would likewise affect scheduling.

Mean running span scores for the tasks with coarticulation and tapping are depicted in Figure 2 (E1D). The effect of the speeded task on memory for the rapid running span digits was significant in both the task with articulatory suppression and the task with tapping. ANOVAs and pairwise comparisons for these simple effects are given in Table 4. [The experiment-specific interaction 
Table 4

Analysis of Variance for Repeated Measures and Subsequent Pairwise Comparisons (Means With Standard Deviations) for Effects of the Speeded Task on Running and Fixed-Length List Memory Span

\begin{tabular}{|c|c|c|c|c|c|c|c|c|c|c|c|c|}
\hline \multirow[b]{3}{*}{ Experiment } & \multirow[b]{3}{*}{ Rate } & \multirow{3}{*}{$\begin{array}{l}\text { Dual } \\
\text { Task }\end{array}$} & & & & & \multicolumn{6}{|c|}{ Pairwise Comparisons } \\
\hline & & & \multicolumn{4}{|c|}{ ANOVA } & \multicolumn{2}{|c|}{ Cont-Anti } & \multicolumn{2}{|c|}{ Cont-Pro } & \multicolumn{2}{|c|}{ Anti-Pro } \\
\hline & & & $d f$ & $d f_{\text {error }}$ & $F$ & $M S_{\mathrm{e}}$ & $M$ & $S D$ & $M$ & $S D$ & $M$ & $S D$ \\
\hline \multicolumn{13}{|c|}{ Running Memory Span } \\
\hline $1 \mathrm{~A}$ & fast & none & 2 & 46 & $7.11^{*}$ & .03 & $.46^{*}$ & .13 & .11 & .11 & $.34^{*}$ & .13 \\
\hline 1B & slow & none & 2 & 40 & 1.41 & .83 & .32 & .22 & .46 & .25 & .14 & .36 \\
\hline $1 \mathrm{C}$ & slow & coart & 2 & 40 & $3.80^{*}$ & .38 & $.48^{*}$ & .19 & $.42^{*}$ & .23 & .06 & .14 \\
\hline & slow & tap & 2 & 40 & $5.84^{*}$ & .42 & $.68^{*}$ & .20 & .26 & .24 & $.42^{*}$ & .16 \\
\hline 1D & fast & coart & 2 & 34 & $3.72^{*}$ & .16 & $.31^{*}$ & .15 & $.37^{*}$ & .14 & .06 & .11 \\
\hline & fast & tap & 2 & 34 & $6.46^{*}$ & .14 & $.41^{*}$ & .14 & $.36^{*}$ & .11 & .05 & .12 \\
\hline \multicolumn{13}{|c|}{ Fixed-Length List Memory Span } \\
\hline \multirow[t]{2}{*}{$2 \mathrm{~A}$} & slow & coart & 2 & 34 & $6.03^{*}$ & .66 & $.94^{*}$ & .33 & $.50^{*}$ & .15 & $.44^{*}$ & .30 \\
\hline & slow & tap & 2 & 34 & 2.47 & .21 & .30 & .19 & .28 & .15 & .02 & .11 \\
\hline \multirow[t]{2}{*}{$2 \mathrm{~B}$} & fast & coart & 2 & 34 & $12.42^{*}$ & .20 & $.68^{*}$ & .17 & $.54^{*}$ & .14 & .14 & .12 \\
\hline & fast & tap & 2 & 34 & $3.57^{*}$ & .24 & $.43^{*}$ & .16 & $.28^{*}$ & .14 & .14 & .14 \\
\hline \multirow[t]{2}{*}{$2 \mathrm{C}$} & fast & none & 2 & 38 & $6.60^{*}$ & .14 & $.39^{*}$ & .13 & $.33^{*}$ & .12 & .06 & .10 \\
\hline & slow & none & 2 & 38 & 2.26 & .12 & .26 & .11 & .21 & .12 & .06 & .09 \\
\hline
\end{tabular}

Note- "Anti," "Pro," and "Cont" = the antipress, propress, and speeded-task control conditions, respectively. "Coart" and "tap" = the coarticulation and knee-tapping dual-task conditions, respectively. ${ }^{*} p<.05$.

between speeded-task condition (antipress, propress, and control) and dual-task distraction during encoding (articulatory suppression and tapping) was evaluated by means of a repeated measures ANOVA but was not significant; $F(2,34)<1, M S_{\mathrm{e}}=.17$, n.s.]

It was the case for both the task with coarticulation and the task with tapping that running memory scores were better in the control condition than in either the antipress or the propress condition, which themselves did not differ. Given the unpredictability of the running span lists and the difficulty of combining rapid presentations with articulatory suppression or tapping, it was the case that the minimal amount of attention required even for the propress condition was enough to disrupt memory retrieval.

\section{EXPERIMENT 2A \\ Slow Fixed-Length Lists With Concurrent Tasks}

Our view is that rehearsal was difficult, if not impossible, in the running span task at the rapid presentation rate in Experiment 1A. We attribute this not only to the speeded presentation rate, but also to the unpredictability of the running span list (see Bunting et al., 2006; Hockey, 1973). In our view, the absence of rehearsal leads to a reliance on attention at the time of retrieval and, therefore, to susceptibility to the antipress version of the speeded task. A similar susceptibility theoretically could be achieved in a fixed-list, slower presentation memory task if articulatory suppression were required. Therefore, our objectives in this next series of experiments were to determine (1) whether the speeded task would interfere with memory for fixed-length lists when articulatory suppression was added and (2) whether predictability would be requisite for this effect.

\section{Results}

As is indicated in Table 1, the participants completed a six-digit memory span task, once with articulatory sup- pression and once with knee tapping. Mean list memory scores for the task with coarticulation and the task with tapping are depicted in Figure 2 (E2A). An ANOVA for repeated measures was used to test whether memory (i.e., proportion correct on the span task) varied as a function of the speeded-task conditions (antipress, propress, and control), the concurrent-task conditions (articulatory suppression and tapping), serial position, or some interaction of these variables. The speeded-task $\times$ concurrent-task interaction, which is critical to our primary hypothesis, was significant $\left[F(2,34)=4.00, M S_{\mathrm{e}}=.04, p<.03\right]$. The locus of this interaction was that the antipress speeded task had a diminishing effect on list memory scores in the task with articulatory suppression, but not in the task with tapping. There was thus a simple effect of the speededtask condition for list memory with articulatory suppression, but not with tapping (see Table 4 for the ANOVAs and pairwise comparisons).

The overall analysis also produced main effects of speeded task, concurrent task, and serial position $\left[F(2,34)=5.64, M S_{\mathrm{e}}=.10, p<.01 ; F(1,17)=216\right.$, $M S_{\mathrm{e}}=.03, p<.01$; and $F(5,85)=61.62, M S_{\mathrm{e}}=.02$, $p<.01$, respectively]. Figure 2 (E2A) shows that performance was highest overall for the control condition and lowest overall for the antipress condition, and that performance was higher with tapping than with articulatory suppression. Figure 3 further shows that the effect of serial positions was curvilinear, thus resembling the results of many previous studies of serial recall (e.g., Page \& Norris, 1998). There was a concurrent-task $\times$ serial position interaction $\left[F(5,85)=17.84, M S_{\mathrm{e}}=.01, p<.01\right]$, which appears to indicate a detrimental effect of suppression, as compared with tapping, especially in the medial serial positions, because bowing in the function was accentuated with suppression. Mean list memory scores (with standard errors) at Serial Positions 1-6 were $.85(.02), .70$ (.02), $.61(.02), .49(.02), .50(.02)$, and $.79(.03)$, respectively, 
for the task with articulatory suppression and $.95(.01)$, $.90(.02), .84(.03), .77(.04), .78(.03)$, and $.93(.02)$, respectively, for the task with tapping. Paired-comparison $t$ tests indicated that scores were significantly lower for the task with articulatory suppression at every serial position ( $\alpha$ was adjusted to .008 for multiple comparisons). There was neither a speeded-task $\times$ serial position interaction nor a speeded-task $\times$ concurrent-task $\times$ serial position interaction $\left[F(10,170)<1, M S_{\mathrm{e}}=.01\right.$, n.s., and $F(10,170)<1, M S_{\mathrm{e}}=.01$, n.s., respectively].

RTs to the anti- and propress decisions were not significantly different but still not perfectly equal, so, as in Experiment $1 \mathrm{~A}$, we entertained the hypothesis that this could be why list memory scores differed in the task with articulatory suppression. To equate RTs for the speeded-task conditions in list memory with articulatory suppression, the 20 trials with the longest RTs among all the trials in the articulatory suppression condition for all the participants in the antipress condition were dropped. Even with the mean RTs for the anti- and propress conditions equated (at $389 \mathrm{msec}$ ), the pattern of results for list memory remained unchanged. Critical to our hypothesis, the ANOVA main effect of the speeded task was still significant $[F(2,34)=$ $\left.6.03, M S_{\mathrm{e}}=.66, p<.01\right]$, and subsequent orthogonal pairwise comparisons still showed that the antipress condition $(M=3.45, S D=0.76)$, but not the propress condition $(M=3.95, S D=0.67)$, differed significantly from the control $(M=4.39, S D=0.77)$.

\section{Discussion}

This experiment successfully replicated the speededtask effect (i.e., lower memory span with the antipress than with the propress), but with a fixed-list memory task with articulatory suppression. Our position here, as in the Experiment 1 series of experiments, is that attention is sometimes needed to convert information from passive storage and/or precategorical sensory memory to a form in which it can be recalled, as when rehearsal is prevented during encoding. The antipress condition introduced competition for attention precisely at the time that it was needed for digit recall and, hence, detracted from list memory scores.

The tapping task was innocuous insofar as it did not prevent rehearsal of the digits and, therefore, did not interfere much with the function of attention to retrieve, store, and recall the digits. Under these circumstances, we think that memory is maintained via a passive storage mechanism, such as phonological memory in Baddeley's (2000) model or the activated portion of long-term memory (which includes both sensory and categorical features) in Cowan's (1995) model. In this case and unlike the situation in which rehearsal is prevented, the contents of passive storage have already been attended and interpreted at the time of encoding, so they are already in a retrievable form and take less attention at the time of retrieval.

Comparison of serial position effects across two very different experiments yielding attention-related effects. The serial position patterns displayed in Figure 3 are telling with regard to the similarities and differences between recall in a fixed-list memory task with articula- tory suppression (the present experiment) and that in a running span task with the rapid presentation rate (Experiment 1A). The recency pattern (i.e., performance at Serial Positions 4-6) is essentially identical in both tasks. The presence of the primacy effect for the fixed-list memory tasks clarifies why the number correct summed across serial positions is higher for fixed lists than for running span (Figure 2, E2A vs. E1A). It is not yet clear from the literature just why the primacy effect occurs. It could be accounted for on the basis of item distinctiveness (Neath, 1999), or it could be tantamount to a primacy gradient (Farrell \& Lewandowsky, 2004; Page \& Norris, 1998). In the former case, the primacy advantage is attributed to the fact that primacy items are distinct in memory because there are no immediately preceding items with which they can become confused. In the latter case, there is superior encoding strength for the first item by virtue of its order and degraded strength for subsequent items in proportion to their displacement from the starting point. Page and Norris further clarified that the primacy gradient could be an effect in which the activation of each new item is diminished because activation must be shared with already existing items, or it could be based on how far each item is from a context marker at the beginning edge of the list. The latter account may be inconsistent with the finding that it is the relative location of an item in a list that is most important for recall, not its absolute distance from the beginning of the list (Henson, 1999). In any case, items for recall in a running span task are not similarly distinct, since they do not come at the beginning of the list (see also Hockey \& Hamilton, 1977).

The serial position patterns are inconsistent with a decay account of forgetting. There was superior recall for the fixed-list items in spite of the fact that rehearsal was prevented via articulatory suppression and the presentation rate was slower than in the running span task. As opposed to our preferred accounts of the primacy effect for fixed-list recall, decay would thus necessarily predict superior performance for the running span task than for the fixed-list task. Of course, it is possible that there is decay obscured by other, more potent factors in recall.

In Experiments 1A and 2A, we obtained effects of the difficulty of a task intervening between stimuli and responses in two very different situations (running span and fixed span with articulatory suppression). The remaining Experiments $2 \mathrm{~B}$ and $2 \mathrm{C}$ allowed us to reveal a more extensive pattern by including various permutations of the task conditions, including predictability of the digit list, speed of the digit presentation, and the presence or absence (and difficulty when present) of distraction during encoding.

\section{EXPERIMENT 2B \\ Fast Fixed-List Memory With Concurrent Tasks}

As is indicated in Table 1, the task requirements remained unchanged from Experiment $2 \mathrm{~A}$, but for the decrease in the presentation rate. Mean digit recall on the anti-, pro-, and no-press (control) speeded-task conditions for the tasks with coarticulation and tapping are depicted in Figure 2B. The effect of the speeded task on memory for the rapidly 
presented fixed-length lists was significant for both the task with articulatory suppression and the task with tapping. ANOVAs and pairwise comparisons for these simple effects are given in Table 4. [The experiment-specific interaction between speeded-task condition (antipress, propress, and control) and dual-task distraction during encoding (articulatory suppression and tapping) was evaluated by means of a repeated measures ANOVA but was not significant; $F(2,34)=1.46, M S_{\mathrm{e}}=.17$, n.s.]

For the task with articulatory suppression, scores in the control condition significantly exceeded scores in the antipress and propress conditions, which themselves did not differ (see Table 4). The pattern was identical for the task with tapping. This effect is similar to the effect for running span at the rapid presentation rate and with articulatory suppression (Experiment 1D). As we argued there, articulatory suppression may add to the demands on attention at the moment of the speeded-task response. This competition might limit the extent to which the focus of attention can zoom out to apperceive the unrehearsed items in sensory or phonological memory at the required time.

Predictability continued to be highly important to memory for the digits. Even with articulatory suppression during encoding and the rapid presentation rate, memory for the digits was still better than in Experiment 1D with the unpredictable running span task. However, predictability alone did not diminish the need for attention during the retention interval, as indicated by the negative effect of the antipress speeded task on memory for digits, either for the task with tapping or for that with articulatory suppression.

\section{EXPERIMENT 2C \\ Fast and Slow Fixed-Length Lists (No Dual Task)}

The concurrent-task conditions (articulatory suppression and tapping) were eliminated from the fixed-length list memory task. Presumably, the participants could thus adopt an active rehearsal strategy, at least when the digits were presented at a sufficiently slow pace, hence mitigating the need for attention during the retention interval. The participants completed the tasks listed in Table 1 (2C).

Mean list memory scores for the fast and slow presentation rates are depicted in Figure 2 (E2C). The scores varied as a function of the difficulty of the speeded task in the rapid presentation rate condition, but not in the slow presentation rate condition. ANOVAs and pairwise comparisons for the simple effects of presentation rate are given in Table 4. [The experiment-specific interaction between speeded-task condition (antipress, propress, and control) and digit presentation rate (rapid and slow) was evaluated by means of a repeated measures ANOVA but was not significant; $F(2,38)<1, M S_{\mathrm{e}}=.14$, n.s.]

The results of this experiment are consistent with our previous observations of the running span task at rapid and slow rates of presentation (Experiments $1 \mathrm{~A}$ and $1 \mathrm{~B}$ ). Namely, the opportunity for rehearsal during encoding in the slow presentation rate condition - either in Experiment $1 \mathrm{~B}$ with the slow-paced running span or here with the slow-paced, fixed-length list task - reduced the need for attention during the retention interval. Although the fixed- length lists were predictable and short by comparison with the running span lists, the antipress speeded task had a small although significant detrimental effect on memory for the lists at the rapid pace, which we attribute to competing demands for attention during the retention interval.

\section{CROSS-EXPERIMENT COMPARISONS}

The effect of the speeded interpolated task on memory for digits was tested a total of 12 times, under different conditions, in the seven previous experiments. The digit memory tasks varied along three important dimensions: (1) the ease of anticipating the number of digits in the list, (2) the digit presentation rate, and (3) the absence or presence of distraction during encoding (and the difficulty of the distraction task when present). The speeded interpolated task provided interference during the retention interval of the digits and varied in the degree of difficulty or attentional demand (antipress was the more difficult condition).

Figure 2 shows all 12 of these conditions. For each span task, an asterisk (*) indicates that the condition shown (antipress or propress) differed significantly from the nopress control condition. A number of main effects pertinent to our primary variables (predictability, presentation rate, and dual-task distraction) are apparent. Predictabilitywhether the digit list was fixed at six items or was long and unpredictable - had a significant effect on performance; scores across all conditions were almost twice as high with the fixed-list task as with the running span task.

The effect from the speed of the presentation rate was more subtle and was most apparent in the tasks without a dual-task component. A visual comparison of the control conditions without a dual task shows that the participants benefited from the ability to rehearse and update during presentation of the running span digits, but not during presentation of the fixed-length list digits. The addition of the antipress interpolated task, however, hurt performance, thus indicating that rehearsal during the encoding interval may not matter as long as the list is relatively short and predictable and attention is available immediately following presentation of the digits.

The articulatory suppression condition clearly hurt performance across the conditions, relative to the conditions without a secondary task during encoding. Tapping, although meant to be a fairly innocuous, repetitious motor activity, appeared to have a small but negative effect on performance in all but the slow-paced, fixed-length list task. The effect was not as substantial as that with articulatory suppression. We attribute this to difficulty coordinating competing motor responses for the knee-tapping and interpolated keypress components of the task.

In addition to these main effects, there is systematic evidence of the three factors (dual-task potency, speed of presentation, and predictability of list length) all working together. In Figure 2, we have labeled groups of conditions with extreme results Group A (no effect of either pro- or antipress task) and Group B (effects of both). Thus, in Group B, fast presentation with either articulatory suppression or unpredictability (running span) produced significant effects of both anti- and propress, as compared with 
the control. Conversely, in Group A, slow presentation either with no dual task or with a mild dual task and predictable presentation (fixed span) produced neither effect. The remaining, intermediate conditions produced an effect of antipress, but not propress. We attribute this pattern to the stability of encoding. When encoding was highly stable, as in Group A, distraction during retrieval made little or no difference. When encoding was not stable, as in Group B and, to a lesser extent, in the remaining tasks, distraction during retrieval made a difference. We hasten to add that not every variable had a consistently strong effect by itself, but Figure 2 shows that the pattern of influences of the variables in combination was clear and in accord with expectations.

\section{GENERAL DISCUSSION}

Experiment $1 \mathrm{~A}$ (and its replication described in that Results section) and Experiment 2A demonstrated that the attentionally demanding antipress decision task impaired working memory when the prepotent tendency to orient to the flashing box did not match the task goal. It is easy to see why encoding and subvocal rehearsal are difficult in a running span procedure with a rapid presentation rate $(\mathrm{Ex}-$ periment 1) or in a fixed-length procedure with a slower presentation rate along with articulatory suppression (Experiment 2). We assume that under these circumstances, attention is needed in the time following the presentation and just preceding the response to extract information from the passive sources of memory (e.g., sensory memory and/ or activated long-term memory) to more meaningful units that can be used in the response. The difficult speeded antipress (opposite-side) task draws attention from retrieval at the critical moment and, therefore, limits memory for the digits. When attention has to "zoom in" to avoid the incorrect, prepotent response in the opposite-side task, it is less available to "zoom out" to apprehend as many digits as possible in the phonological stream at the same time.

The disadvantage of the antipress condition, relative to the propress condition, was also observed in Experiment $1 \mathrm{C}$, the slow-paced running span task with tapping. This time, encoding and rehearsal were possible, but there was more than one attentional demand at recall. At the offset of the digits, which was unpredictable, the participants had to coordinate the speeded-task response while coordinating the tapping response. The confluence of these factors was detrimental to recall, but more so in the antipress condition than in the propress condition.

One might think that a role of attention in short-term memory retrieval can be taken for granted, but we found that the conditions needed to observe a fleeting use of attention for retrieval are delicate. In Experiment 2A, there was no effect of pro- or antipress tasks for the recall of fixed-length lists presented during tapping (as opposed to articulatory suppression). This suggests that the amount of attention that is needed for retrieval is greater when articulation is blocked than when it is not blocked. No effect of attention was observed in two other instances in which rehearsal presumably was possible (see Figure 2 and Experiments $1 \mathrm{~B}$ and $2 \mathrm{C}$ ). When rehearsal is possible, as in these conditions, it can be used to maintain the memoranda in a passive store, such as phonological memory in Baddeley's (2000) model or the activated portion of long-term memory (which includes both sensory and categorical features) in Cowan's (1995) model. Thus, the effect of attention we have observed was not general across these tasks.

It turned out that negative effects of antipress and articulatory suppression were not always absolute, nor were the effects of propress and tapping always benign. Rather, the most reasonable conclusion to reach on the basis of our data seems to be that the various influences on performance come in degrees. The propress responses and tapping had some detrimental effect on performance, but not as much as antipress and articulatory suppression. We found that the participants could engage in even the antipress speeded task with little or no detectable cost when there was unlimited time in which to make the speeded-task response (see the discussion following Experiment 1A) or when rehearsal was not blocked; for instance, as when the running span or list memory items were played slowly and in the absence of any concurrent-task distraction (see Experiments 1B and 2C). Conversely, even the propress may be attention demanding if multiple tasks have to be scheduled under time pressure (e.g., attending to rapidly presented digits in an articulatory suppression condition; Experiments 1D and 2B). These results are consistent with other research showing that when given the opportunity, participants have remarkable flexibility in how they allocate their attention among multiple complex tasks (Barrouillet, Bernardin, \& Camos, 2004; Friedman \& Miyake, 2004a; Gillie \& Broadbent, 1989).

The ability to recover following response conflict has been ascribed to executive control processes (Stürmer, Seiss, \& Leuthold, 2005). The likelihood of making an error when there is a response conflict probably depends on the extent to which one has been primed to expect a response match. We would anticipate a larger effect from the response mismatch had we mixed antipress and propress trials, rather than testing them in discrete blocks, especially if a predominant number of the trials were propress (cf. the disproportionate number of congruent trials in Kane \& Engle's, 2003, research on the Stroop effect).

The results are consistent with those in prior research demonstrating a relationship between attentional control and goal maintenance (see Engle, 2002). Several recent studies have shown that performance on traditional complex working memory span tasks is positively related to some largely attentional phenomena, including lapses in focused attention in a dichotic listening paradigm, visualorienting errors in the antisaccade paradigm, and the Stroop effect (for examples of each of these, see Conway, Cowan, \& Bunting, 2001; Kane, Bleckley, Conway, \& Engle, 2001; and Kane \& Engle, 2003, respectively). On the surface, at least, tasks such as these have little similarity to span tasks or other memory tasks in general, but such findings suggest that attentional control is important to the criterion validity of working memory. One explanation of this finding is that goal maintenance and working memory storage rely, to some extent, on the same resource, which may be allocation of the focus of attention (Cowan, 1999, 2001). The working memory theory of Baddeley (2000) 
also might accommodate the present results by sticking to the assumption that the episodic buffer depends on attention (like long-term episodic memory; see Cowan, 1995) and is, therefore, more susceptible to distraction than are the phonological and visuospatial buffers.

One other study supports the point we are making, in the converse manner, by showing an effect of storage on processing. Eenshuistra, Ridderinkhof, and van der Molen (2004) used pro- and antisaccade tasks and showed that the elderly were impaired in antisaccade task performance only when they had a concurrent storage load during the processing task. The memory load apparently made it difficult for them to concentrate on the goal maintenance task, confirming the proposal (Cowan et al., 2005) that both goal maintenance and working memory storage rely on a common resource, such as attention.

Future work should address the criterion validity of running span and ordinary span with articulatory suppression. Cowan et al. (2005) recently showed that running span, at least at the rapid presentation rate, is an accurate and reliable measure of working memory and has good criterion validity. There is an ample literature suggesting that suppressing rehearsal may be critical for the potency of working memory tasks as predictors of cognitive aptitude and that the use of attention for storage and recall might be the critical factor defining the best working memory tests.

We have argued that the running span task and the fixedlength list task with articulatory suppression measure the scope (i.e., capacity) of attention. That is, attention must be used to capture as many digits as possible from a sensory or phonological memory trace at the end of the list, before that representation fades. It follows, therefore, that individual differences in the scope of attention underlie the criterion validity of such span tasks (Cowan et al., 2005). The present experiments, in all but the most stable encoding conditions, showed that the difficult speeded task limited the mnemonic function of attention and, thus, the span tasks no longer reflected the scope of attention.

\section{CONCLUSION}

Overall support for the use of attention at retrieval must be made cautiously at this point. In sum, a brief visual distraction during the retention interval in a running span task (Experiment 1A) or a fixed-list-length memory task with articulatory suppression (Experiment 2A) namely, choosing the opposite side of the screen relative to a flashing box - was enough to interfere with recall. Other factors mitigated this effect, as when there was the opportunity for rehearsal during encoding (the slow presentation with no dual task in Experiments $1 \mathrm{~B}$ and $2 \mathrm{C}$ or with tapping in Experiment 2A). Overall, the interpolated task effect suggests that attentional control, as necessary for goal maintenance, and temporary storage may share an attentional resource. Consistent with Cowan (2001), attention might zoom in to maintain a goal or zoom out to apprehend multiple items. Attention can be used for goal maintenance in the face of distraction, as in the antipress response in the speeded task, but only at a cost to the use of attention for the apprehension of items to be recalled.

\section{AUTHOR NOTE}

This work was supported by Grant R01 HD-21338 awarded to N.C. from the National Institutes of Health. M.F.B. was supported by a postdoctoral fellowship at the University of Missouri from the Missouri Rehabilitation Research Training Program (Kristofer Hagglund, P.I.), the National Institute of Child Health and Human Development, and the National Institutes of Health (Grant 2 T32 HD07460-09). The authors thank Nash Unsworth for commenting on a draft of the manuscript. Address correspondence to either N. Cowan, Department of Psychological Sciences, University of Missouri, 207 McAlester Hall, Columbia, MO 65211 , or M. F. Bunting, who is now at the University of Maryland Center for Advanced Study of Language, P.O. Box 25, College Park, MD 65211 (e-mail: cowann(a)missouri.edu or mbunting@casl.umd.edu).

\section{REFERENCES}

BADDELEY, A. [D.] (1986). Working memory. Oxford: Oxford University Press.

BADDELEY, A. [D.] (2000). The episodic buffer: A new component of working memory? Trends in Cognitive Sciences, 4, 417-423.

BADDELEY, A. D. (2007). Working memory, thought, and action. New York: Oxford University Press.

BADDELEY, A. D., \& Hitch, G. (1974). Working memory. In G. H. Bower (Ed.), The psychology of learning and motivation (Vol. 8, pp. 47-89). New York: Academic Press.

Baddeley, A. D., \& Logie, R. H. (1999). Working memory: The multiple-component model. In A. Miyake \& P. Shah (Eds.), Models of working memory: Mechanisms of active maintenance and executive control (pp. 28-61). Cambridge: Cambridge University Press.

Barrouillet, P., Bernardin, S., \& Camos, V. (2004). Time constraints and resource sharing in adults' working memory spans. Journal of Experimental Psychology: General, 133, 83-100.

Bunting, M. F., Cowan, N., \& Saults, J. S. (2006). How does running memory span work? Quarterly Journal of Experimental Psychology, 59, 1691-1700.

Conway, A. R. A., Cowan, N., \& Bunting, M. F. (2001). The cocktail party phenomenon revisited: The importance of working memory capacity. Psychonomic Bulletin \& Review, 8, 331-335.

Cowan, N. (1984). On short and long auditory stores. Psychological Bulletin, 96, 341-370.

Cowan, N. (1988). Evolving conceptions of memory storage, selective attention, and their mutual constraints within the human information processing system. Psychological Bulletin, 104, 163-191.

Cowan, N. (1995). Attention and memory: An integrated framework. New York: Oxford University Press.

Cowan, N. (1999). An embedded-processes model of working memory. In A. Miyake \& P. Shah (Eds.), Models of working memory: Mechanisms of active maintenance and executive control (pp. 62-101). Cambridge: Cambridge University Press.

Cowan, N. (2001). The magical number 4 in short-term memory: A reconsideration of mental storage capacity. Behavioral \& Brain Sciences, 24, 87-185.

Cowan, N. (2005a). Selective attention tasks in cognitive research. In A. Wenzel \& D. C. Rubin (Eds.), Cognitive methods and their application to clinical research (pp. 73-96). Washington, DC: American Psychological Association.

Cowan, N. (2005b). Working memory capacity. New York: Psychology Press.

Cowan, N., Cartwright, C., Winterowd, C., \& Sherk, M. (1987). An adult model of preschool children's speech memory. Memory \& Cognition, 15, 511-517

Cowan, N., Elliott, E. M., Saults, J. S., Morey, C. C., Mattox, S., Hismuatullina, A., \& Conway, A. R. A. (2005). On the capacity of attention: Its estimation and its role in working memory and cognitive aptitudes. Cognitive Psychology, 51, 42-100.

Daneman, M., \& CARPEnter, P. A. (1980). Individual differences in working memory and reading. Journal of Verbal Learning \& Verbal Behavior, 19, 450-466.

Eenshuistra, R. M., Ridderinkhof, K. R., \& van der Molen, M. W. (2004). Age-related changes in antisaccade task performance: Inhibitory control or working-memory engagement? Brain \& Cognition, 56, $177-188$. 
ENGLE, R. W. (2002). Working memory capacity as executive attention. Current Directions in Psychological Science, 11, 19-23.

Engle, R. W., Kane, M. J., \& Tuholski, S. W. (1999). Individual differences in working memory capacity and what they tell us about controlled attention, general fluid intelligence and functions of the prefrontal cortex. In A. Miyake \& P. Shah (Eds.), Models of working memory: Mechanisms of active maintenance and executive control (pp. 102-134). Cambridge: Cambridge University Press.

ERICSSON, K. A., \& KinTSCH, W. (1995). Long-term working memory. Psychological Review, 102, 211-245.

FARReLl, S., \& LeWANDOWSKy, S. (2004). Modelling transposition latencies: Constraints for theories of serial order memory. Journal of Memory \& Language, 51, 115-135.

Friedman, N. P., \& MiYaKe, A. (2004a). The reading span test and its predictive power for reading comprehension ability. Journal of Memory \& Language, 51, 136-158.

Friedman, N. P., \& MiYAKe, A. (2004b). The relations among inhibition and interference control functions: A latent-variable analysis. Journal of Experimental Psychology: General, 133, 101-135.

Gillie, T., \& Broadbent, D. E. (1989). What makes interruptions disruptive? A study of length, similarity, and complexity. Psychological Research, 50, 243-250.

Hallett, P. E. (1978). Primary and secondary saccades to goals defined by instructions. Vision Research, 18, 1279-1296.

Henson, R. N. A. (1999). Positional information in short-term memory: Relative or absolute? Memory \& Cognition, 27, 915-927.

HockeY, R. (1973). Rate of presentation in running memory and direct manipulation of input-processing strategies. Quarterly Journal of Experimental Psychology, 25, 104-111.

Hockey, R., \& Hamilton, P. (1977). The basis of the primacy effect: Some experiments with running memory. Quarterly Journal of Experimental Psychology, 29, 49-63.

Kane, M. J., Bleckley, M. K., Conway, A. R. A., \& Engle, R. W. (2001). A controlled-attention view of working-memory capacity. Journal of Experimental Psychology: General, 130, 169-183.

KANE, M. J., \& ENGLE, R. W. (2003). Working-memory capacity and control of attention: The contributions of goal neglect, response competition, and task set to Stroop interference. Journal of Experimental Psychology: General, 132, 47-70.

Kane, M. J., Hambrick, D. Z., Tuholski, S. W., Wilhelm, O., Payne, T. W., \& ENGLE, R. W. (2004). The generality of working memory capacity: A latent-variable approach to verbal and visuospatial memory span and reasoning. Journal of Experimental Psychology: General, 133, 189-217.

Loftus, G. R., \& Masson, M. E. J. (1994). Using confidence intervals in within-subject designs. Psychonomic Bulletin \& Review, 1, 476-490.

NEATH, I. (1999). Modelling the disruptive effects of irrelevant speech on order information. International Journal of Psychology, 34, 410-418.

Nelson, D. L., \& Goodman, L. B. (2003). Disrupting attention: The need for retrieval cues in working memory theories. Memory \& Cognition, 31, 65-76.

OBErauer, K. (2005). Control of the contents of working memory-A comparison of two paradigms and two age groups. Journal of Experimental Psychology: Learning, Memory, \& Cognition, 31, 714-728.

PAGe, M. P. A., \& Norris, D. [G.] (1998). The primacy model: A new model of immediate serial recall. Psychological Review, 105, 761-781.

Pollack, I., Johnson, L. B., \& KNAFF, P. R. (1959). Running memory span. Journal of Experimental Psychology, 57, 137-146.

Roberts, R. J., Jr., Hager, L. D., \& Heron, C. (1994). Prefrontal cognitive processes: Working memory and inhibition in the antisaccade task. Journal of Experimental Psychology: General, 123, 374-393.

Shiffrin, R. M. (1988). Attention. In R. C. Atkinson, R. J. Herrnstein, G. Lindzey, \& R. D. Luce (Eds.), Stevens' Handbook of experimental psychology (Vol. 2, pp. 739-811). New York: Wiley.

Stürmer, B., SeIss, E., \& Leuthold, H. (2005). Executive control in the Simon task: A dual-task examination of response priming and its suppression. European Journal of Cognitive Psychology, 17, 590-618.

TuRner, M. L., \& ENGLE, R. W. (1989). Is working memory capacity task dependent? Journal of Memory \& Language, 28, 127-154.

Watkins, M. J., Watkins, O. C., Craik, F. I. M., \& Mazuryk, G. (1973). Effect of nonverbal distraction on short-term storage. Journal of Experimental Psychology, 101, 296-300.

\section{NOTE}

1. We believe that time pressure was critical in preventing covert verbal rehearsal. In the absence of time pressure in our speeded-task decision, the participants could delay their response in order to rehearse or otherwise prepare their response on the running span task. For instance, it is possible that they might delay the responses until the list-final digit sequence could be memorized, for subsequent recall from what Ericsson and Kintsch (1995) have termed "long-term working memory" (see also Cowan, 1995; Nelson \& Goodman, 2003). As evidence of this, consider an experiment in which we replicated most of the Experiment 1 procedure, but with unlimited time for what we have otherwise called the "speeded-task" response. The antipress response did not affect running span performance in the absence of time pressure. Response speeds were more than a half second slower than those in Experiment 1. Running span scores, which were for trials with a correct speeded-task response only, did not significantly differ from the antipress $(M=2.37,95 \% \mathrm{CI}=$ $\pm 0.17)$ or the propress $(M=2.49,95 \% \mathrm{CI}= \pm 0.17)$ responses $[\Delta M=$ $0.12, S E=0.10 ; t(27)=1.06$, n.s.]. Antipress $(M=975 \mathrm{sec}, S D=$ $506)$ and propress $(M=1,001 \mathrm{sec}, S D=492)$ RTs did not significantly differ $[\Delta M=26 \mathrm{msec}, S E=58.2 ; t(27)<1$, n.s. $]$. The results must be interpreted with some caution, because the experiment did not include a no-press control condition.

\section{APPENDIX}

Methodological Details of the Experiment 1A Replication and Experiment 1B

We hypothesized that memory for irrelevant early list items (proactive interference) may contribute to the difficulty in recalling the last six items in a running span task. To test this hypothesis, we tested participants in two sets of running span tasks. Both sets included the speeded-task practice, running span with the speeded task, and a running-span-only control. In the first set of tasks, the digits were completely random (the procedure was identical to that described in Experiment 1A). In the second set of tasks, we manipulated the novelty of the digits. In one block of running span trials, the first three of six to-be-recalled digits were novel to that trial. In a second block of trials, the last three of six to-be-recalled digits were novel to that trial. We conducted this experiment with the digits at a rapid presentation rate (4 digits/sec), which is the task reported in the replication of Experiment $1 \mathrm{~A}$. We also conducted this experiment with the digits at a slow presentation rate (1 digit/sec), which is the task reported in Experiment 1B. Although we found an effect of novelty in both experiments, the results of that manipulation are not easily interpretable and will require further experimentation. 